\title{
Bioclimatic residence design in the Xanthi region
}

\author{
K. Lantitsou \& D. Christodoulou \\ Transport Work and Transport Sector Department of Civil Engineers, \\ Polytechnic Faculty, Dimokritus University of Thrace, Greece
}

\begin{abstract}
With the important climatic changes in the planet, the bioclimatic perception for building planning is considered essential. The bioclimatic architecture studies building planning, based on the local climate, aiming at the saving of energy. This inquiring work analyses the bioclimatic setting up of a residence in the region of Xanthi, taking into consideration the local climatic conditions. The plot of the building is concrete and with intense bent. The building is placed in such a way, that daily use rooms (kitchen, living room, dining room) are located on the southern side of the house. After preparation of the final ground plan, southern openings of daily use accommodation are calculated based on the classic type of openings. On the ground floor and in the floor, Trombe walls are applied. On the southern side of the house, a conservatory is incorporated, while for the shading of spaces at summertime shadings are placed. Southwest of the residence, the planting of deciduous trees is planned, while on the north side, the planting of evergreen trees is prearranged.

Keywords: eco-architecture and bioclimatic design.
\end{abstract}

\section{Introduction}

With the important climatic changes in the planet, the bioclimatic perception for the buildings planning is considered essential. The bioclimatic architecture studies the buildings planning, based in the local climate, aiming at saving energy. This inquiring work analyses the bioclimatic setting up of a residence in the region of Xanthi, taking into consideration the local climatic conditions.

The plot of the building is concrete and with intense bent. The building is placed in such a way so that daily use rooms (kitchen, living room, dining room) 
are located on the southern side of house. After the preparation of the final ground plan, the southern openings of daily use accommodation are calculated based in the classic type of openings [1].

On the ground floor and in the floor, Trombe walls are applied. On the southern side of the house, a conservatory is incorporated, while for the shading of spaces at summertime, shadings are placed. Southwest of the residence, the planting of deciduous trees is planned, while on the north side, the planting of evergreen trees is prearranged.

\section{Planning methodology}

Bioclimatic architecture is mainly the result of a completed designing and constructional process that exploits a wide spectrum of environmental parameters. Planning a two-floored bioclimatic building in Xanthi, the following bioclimatic interventions took place:

First in the manufacturing process of a bioclimatic residence was the choice of plot. During the foundation phase suitable shafts were manufactured that buried in the floor and only the driver that leads radon out of the building comes out of it.

The building was placed facing from east to west $(\mathrm{E} \rightarrow \mathrm{W})$, thus resulting in a bigger surface to the south, for the collection of solar heat during winter.

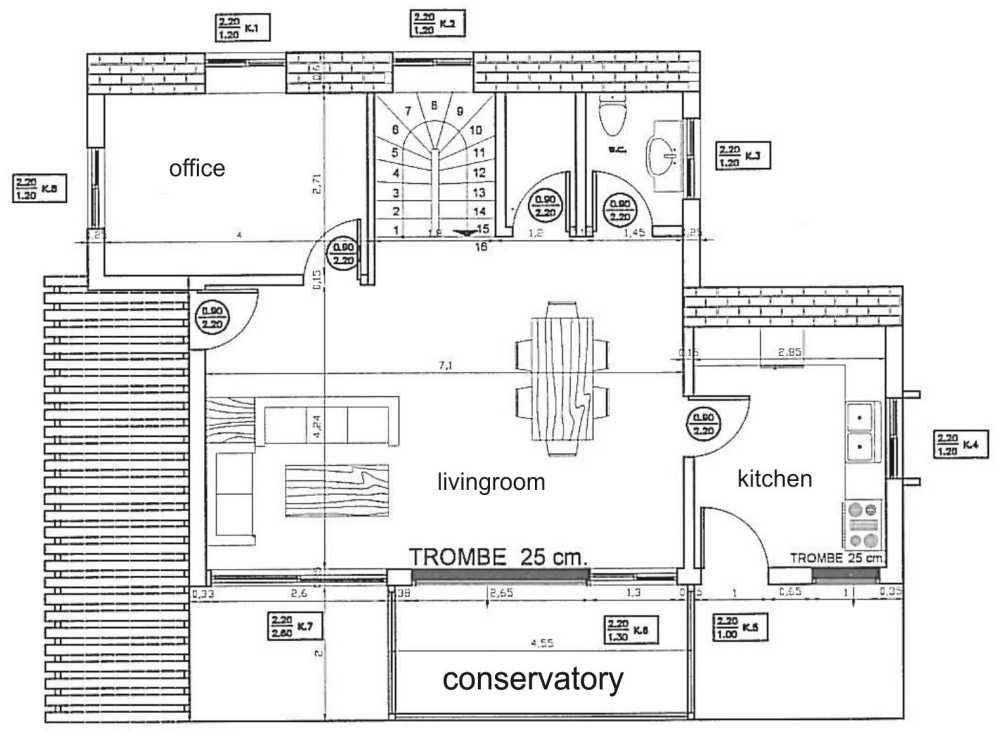

Figure 1: Ground floor plan.

The ground plan drawing of internal spaces, organized in such a way that all the daily used rooms are placed on the southern side of the building in order to ensure the desirable internal temperatures. In contrast, rooms of limited use, which do not require high levels of heat, are placed in the intermediary thermic 


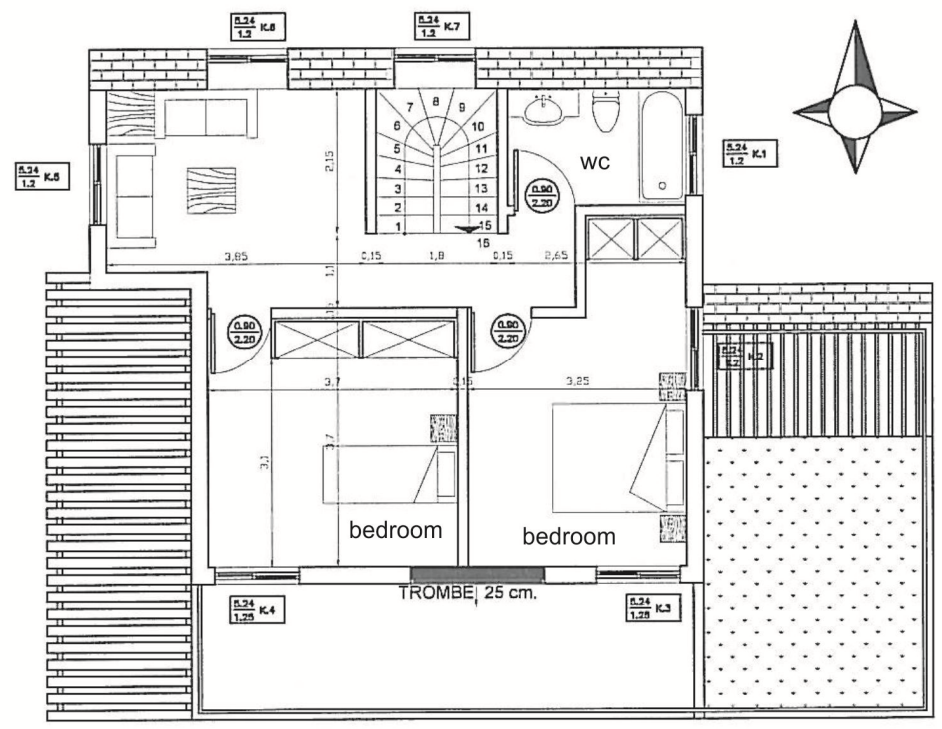

Figure 2: $\quad$ First floor plan.

area. The remainder auxiliary rooms are placed on the northern side of the building for protection while insulating the rest of the rooms.

Southern openings are calculated and placed targeting to the collection of heat from the sun during the wintry months and the existence of suitable lighting. Small openings were also placed in the northern side of the building, to ensure ventilation to the whole area. Better ventilation conditions and consequently natural cooling is achieved when airflow follows a differential movement through the area, because, on the one hand we have uniform distribution of current, and, on the other, cooling to all the space. For the openings that are placed in more orientations that are unfavourable, north, east, west we placed double panes, in which the profits from the sun are better than the thermic losses and their contribution is positive in the thermic balance at $23 \%$, during winter [2]. The type used for the calculation of southern openings is the following:

$$
\mathrm{E}_{\text {opening }} / \mathrm{E}_{\text {ground plan }}=0.21
$$

Living room: $\mathrm{E}_{\text {ground plan }}=3.60 \times 7.10=25.56 \mathrm{~m}^{2}$

$$
25.56 \times 0.21=5.36
$$

$$
\text { Length of opening }=5.36 / 2.20=2.43 \mathrm{~m}
$$

Kitchen: $\mathrm{E}_{\text {ground plan }}=3.60 \times 2.85=10.26 \mathrm{~m}^{2}$

$$
10.26 \times 0.21=2.15
$$

$$
\text { Length of opening }=2.15 / 2.20=1.00 \mathrm{~m}
$$

$$
\text { Bedroom: } E_{\text {ground plan }}=(3.70 \times 3.25)+(1.50 \times 0.85)=13.30 \mathrm{~m}^{2}
$$




$$
\begin{gathered}
13.30 \times 0.21=2.15 \\
\text { Length of opening }=2.79 / 2.20=1.25 \mathrm{~m}
\end{gathered}
$$

A conservatory in the southern side of the building incorporated $4.55 \mathrm{~m} \mathrm{x}$ $2.00 \mathrm{~m}$ ). The wall of thermic storage constitutes the bisector wall between the conservatory and the main building resulting in more effective the operation of conservatory trapping the solar radiation and transporting the heat in all internal walls via a ventilators system. The type used for the calculation of the conservatory is the following:

$$
E_{\text {greenhouse }} / \mathrm{E}_{\text {interior }}=0.50
$$

Conservatory glass-surface area: $13.5 \mathrm{~m}^{2}$

A thermic storage wall (trombe) is placed in the southern side of the building. The functionality of this wall is based on the geyser phenomenon and realized with the circulation of air in the space between the glass and the wall due to the differences of temperature. The trombe wall presents enough advantages because of its entire manufacturing and its relatively important performance. The type used for the calculation of the trombe wall is the following:

$$
\begin{gathered}
E_{\text {wall }} / E_{\text {floor }}=0.28 \\
\text { Kitchen: } E_{\text {floor }}=10.26 \mathrm{~m}^{2} E_{\text {wall }}=10.26 \mathrm{~m}^{2} \times 0.28=2.87 \mathrm{~m}^{2} \\
\text { Length of the wall }=2.87 / 2.88=1,00 \mathrm{~m} \\
\text { Living room: } \mathrm{E}_{\text {floor }}=25.56 \mathrm{~m}^{2} \mathrm{E}_{\text {wall }}=25.56 \mathrm{~m}^{2} \times 0.28=7.15 \mathrm{~m}^{2} \\
\text { Length of the wall }=7.15 / 2.88=2.48 \mathrm{~m} \\
\text { Bedroom: } \mathrm{E}_{\text {floor }}=13.3 \mathrm{~m}^{2} \mathrm{E}_{\text {wall }}=13.04 \mathrm{~m}^{2} \times 0.28=3.72 \mathrm{~m}^{2} \\
\text { Length of wall }=3.72 / 2.88=1.3 \mathrm{~m}
\end{gathered}
$$

Sun-protective shadings are placed in the windows in order to avoid overheating during summertime. On the southern side, constant horizontal shading is placed. The width of the shading was taken into serious consideration so that during summertime a full shade of the openings is ensured, while in the winter a passage to the sun is allowed into the area. An eastern oriented mobile vertical venetian blind is positioned, which is more effective since the sun is low near the horizon during summertime. The existence of sunlight during winter is the reason why a mobile sun-protection is selected.

A planted loft manufactured above the space of the kitchen, which is a complicated thermic system that presents important thermal insulation attributes for both winter and summer. The planted loft offers important protection from noise thus contributing in the rational management of rainwater and shapes an aesthetically pleasant space - healthy and useful.

A stone wall manufactured in the north area where the heat or the cold enters the interior of building in double time concerning a formal wall with insulation. 


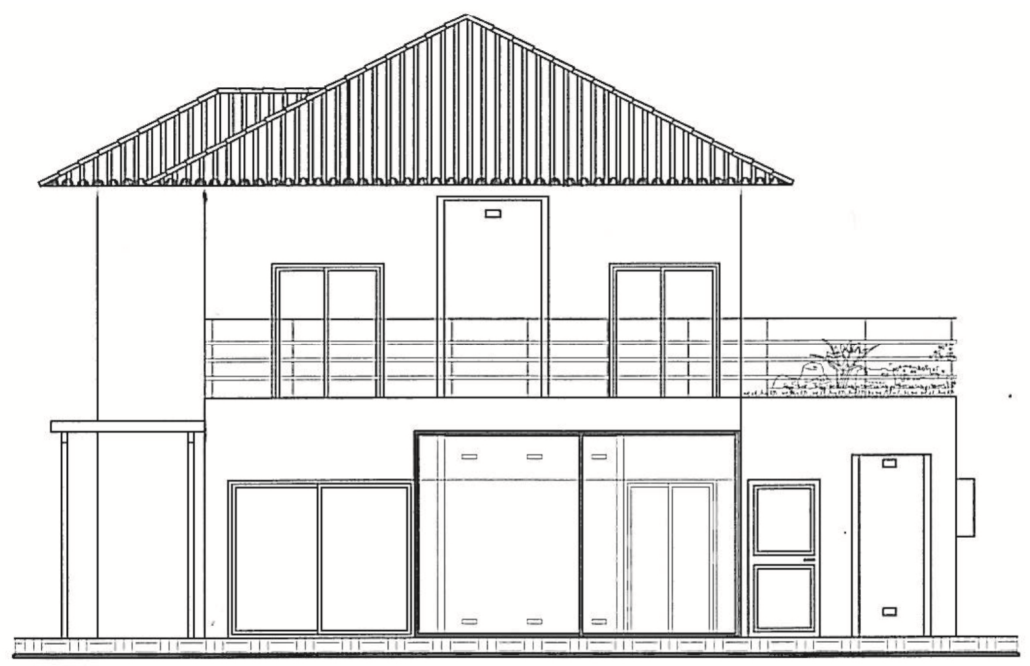

Figure 3: $\quad$ Basic house view.

Deciduous trees are suitably planted in the southern, south-eastern and in the south-western sides of building so that the sun light is interrupted in the summer months. The vegetation simultaneously moderates the exterior temperature due to the absorption from the foliage. A suitable north planting with evergreen trees also took place as an obstacle to the cold wintry winds. Plants placed not only for aesthetic reasons but also for the creation of oxygen and negative ions precious for human life. Negative ions offer positive energy and a revitalizing feeling.

Another basic element is essential for the structural materials. This is the importance that they must be environmental friendly, recyclable and not causing problems in human health. The building frame is important to be robust; allocating a big thermic mass and good heat insulation. The characteristic element of bioclimatic residences is the use of a strengthened thermic mass and good insulation with the use of as much as possible ecological heat insulation materials. The result is the preservation of a stable internal temperature and internal humidity in enough low levels.

The heat insulation has an important effect in the thermic record, planning and functioning of heating systems but also for fuel needs and relaxation to the users. Overinflated polyester, which belongs in the generation of ecological materials with a high sound absorption and heat insulation faculty, is used to ensure heat insulation of the building. This material is shaped into various densities and thicknesses in order to achieve the desirable acoustic characteristics.

"Cotto" type ceramic floorings were used, which are clearly an ecological product and are "cooked ground", "tile of flooring", and we can find it either in natural form or out-enamelled. 
Furthermore, ceramic flour was added in our mortar which lends to the increase of its resistance and resistibility in time. Moreover, it has a grainy texture and natural chromatic nuances.

The rest of the energy that the building needs is obtained from photovoltaic systems that will be placed and they are capable of changing the solar energy into electricity with the help of photovoltaic phenomenon.

\section{Conclusion}

Greece is a region with the benefit of a marvellous climate. This climate supports the implementation of bioclimatic architecture principles with positive results in the energy performance of the buildings.

Buildings can achieve much more with less or null compatible energy consumption. The achievement of reduction of energy consumption and protection of environment objectives is possible without necessarily sacrificing the levels of comfort and aesthetic, which are most desirable.

The bioclimatic architecture is an imperative necessity for most developing societies nowadays. The quality of living in a bioclimatic house cannot be compared with the conventional one; whatever the quantity of machinery they are provided with in order to light, ventilate, warm and cool them up.

\section{References}

[1] Tsipiras, K. and Th., Ecological architecture, Kedros editions, Athens, 2005.

[2] Andreadaki, E., Bioclimatic Planning, University Studio Press Publications, Thessaloniki, pp. 63-129, 2006. 